\title{
Thermal, Spectroscopic, and Crystallographic Analysis of Mannose- Derived Linear Polyols
}

\author{
Ida Mattsson, ${ }^{\dagger}$ Manu Lahtinen, ${ }^{\ddagger}$ Anssi Peuronen, ${ }^{\ddagger}$ Abhijit Sau, ${ }^{\dagger, \S}$ Andreas Gunell, ${ }^{\dagger}, \#$ \\ Tiina Saloranta-Simell, ${ }^{\dagger}$ and Reko Leino ${ }^{*}{ }^{\dagger}$ (이 \\ †Johan Gadolin Process Chemistry Centre, Laboratory of Organic Chemistry, Åbo Akademi University, Turku FI-20500, Finland \\ ${ }^{\ddagger}$ Department of Chemistry, University of Jyväskylä, Jyväskylä FI-40014, Finland
}

\section{Supporting Information}

\begin{abstract}
The major diastereomer formed in the Barbier-type metal-mediated allylation of D-mannose has previously been shown to adopt a perfectly linear conformation, both in solid state and in solution, resulting in the formation of hydrogen-bonded networks and subsequent aggregation from aqueous solution upon stirring. Here, a comprehensive study of the solid state structure of both the allylated D-mannose and its racemic form has been conducted. The binary melting point diagram of the system was determined by differential scanning calorimetry analysis, and the obtained results, along with structure determination by single crystal X-ray diffraction, confirmed that allylated mannose forms a true racemate. Further examination by powder X-ray diffraction and CP MAS ${ }^{13} \mathrm{C}$ NMR spectroscopy revealed polymorphism both in the pure enantiomer and in the

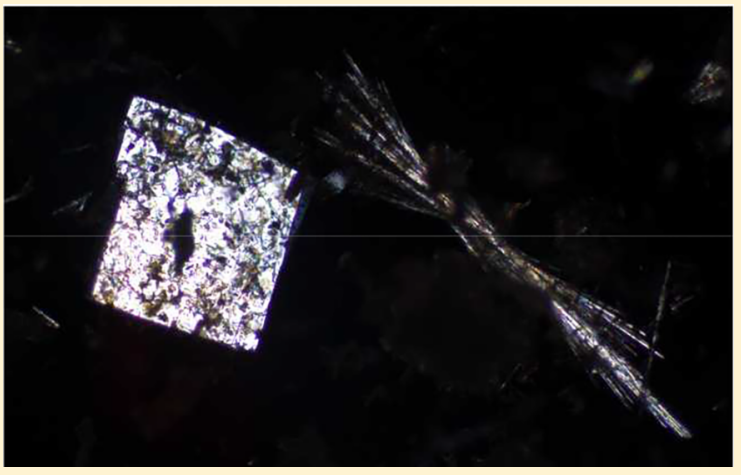
racemate. In addition, the propargylated and hydrogenated analogues of allylated D-mannose were prepared and subjected to thermal and spectroscopic analyses. The crystal structure of the propargylated compound was successfully determined, showing a linear molecular conformation similar to that found for allylated D-mannose. Both new compounds likewise display aggregation behavior in water, further verifying that the low-energy linear conformation plays a significant role in this unusual behavior of these rodlike mannose derivatives.
\end{abstract}

\section{INTRODUCTION}

Co-crystallization of enantiomers, the nonsuperimposable mirror images of a chiral compound, from racemic solutions can generally result in three different outcomes: (1) Formation of a true racemate; (2) conglomerate; or (3) solid solution, also called a pseudoracemate (Figure 1). ${ }^{1}$ In a true racemate, which is the most common of the three, the enantiomers have higher affinities for the opposite enantiomer than for themselves. Crystallization of a true racemate thereby provides crystals consisting of both enantiomers in equal ratio, organized in a highly ordered array. In conglomerates, both enantiomers have higher affinities for themselves rather than the opposite enantiomer. This results in the formation of a physical mixture of enantiomerically pure crystals. Approximately 5-10\% of racemic organic mixtures form conglomerates. ${ }^{2}$ In solid solutions, major differences between the affinities of the enantiomers are not observed. The resulting crystals typically consist of both enantiomers in equal ratios, but in a less ordered manner than in a true racemate. ${ }^{3}$ Solid solutions are the least common form of racemates. The composition of the crystal unit cell of a racemate can be elucidated by studying the single crystal X-ray structures or powder X-ray diffraction (PXRD) patterns of the corresponding compounds. ${ }^{4}$

The racemic composition and character of a chiral compound can also be determined by other techniques. Most commonly, binary melting point diagrams (BMPD) and ternary solubility diagrams are used for categorization of a racemate. ${ }^{5}$ BMPDs are usually obtained by measuring the melting points of mixtures with known enantiomeric ratio by differential scanning calorimetry (DSC). The appearance of the diagram then reveals which form of the racemic compositions the system adopts (Figure 2). ${ }^{5}$ The melting point of a true racemate $\left(T_{\text {rac }}\right)$ can be higher than, equal to, or lower than that for the pure enantiomers, and a clear eutectic melting $\left(T_{\text {eut }}\right)$ is seen in the diagram. A conglomerate always has a lower melting point than the corresponding enantiomers. The melting point of a solid solution can be higher than, equal to, or lower than that for the enantiomers, but solid solutions lack eutectic melting.

Several crystalline organic compounds are known to exhibit polymorphism, defined as the existence of more than one crystal structure for a specific compound. ${ }^{6}$ Different polymorphs of the chemically equal substance may vary significantly in their melting points, solubility behavior, and bioavailability. In order to identify and structurally determine the different polymorphs, thermal analysis techniques are often combined

Received: February 17, 2018

Revised: April 6, 2018

Published: April 9, 2018 

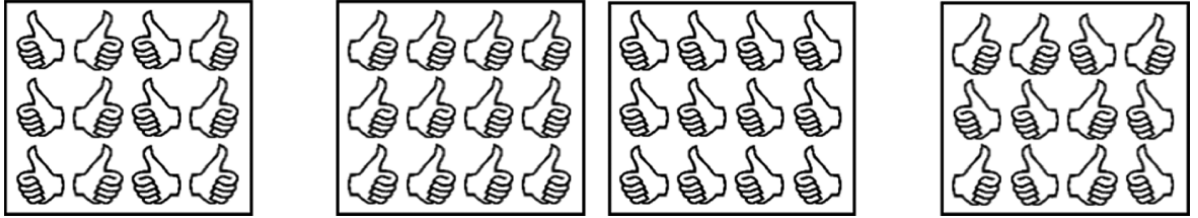

Figure 1. Crystal compositions of true racemate (left); conglomerate (middle); solid solution (right), here represented by right and left hands.
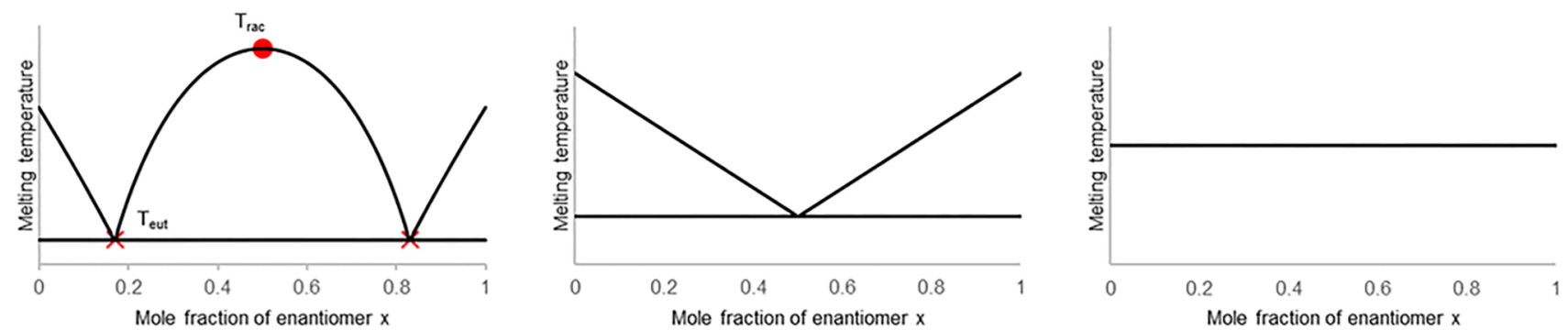

Figure 2. Binary phase diagrams of a true racemate (left); conglomerate (middle); and ideal solid solution (right).

with other characterization methods, such as PXRD, hot stage microscopy (HSM), infrared or Raman spectroscopy, and single crystal X-ray diffraction. ${ }^{8}$ Recently, solid state ${ }^{13} \mathrm{C}$ NMR spectroscopy has also emerged as an important tool for identification and characterization of polymorphs. ${ }^{9,10}$ For example, CP MAS ${ }^{13} \mathrm{C}$ NMR spectra of the pure enantiomers and their corresponding racemate have in several cases been shown to differ significantly, opening new possibilities for use of this technique as a tool for identification of the nature of racemic mixtures. ${ }^{11,12}$

Recently, we reported that the diastereomerically pure allylated D-mannose derivative 1a (Figure 3) manifests rodlike<smiles>C=CCC(O)C(O)[C@H](O)[C@H](O)[C@H](O)CO</smiles>

$1 \mathrm{a}$<smiles>C#CCC(O)C(O)[C@H](O)[C@H](O)C(O)CO</smiles><smiles>CCCC(O)C(O)C(O)[C@H](O)C(O)CO</smiles>

Figure 3. Structures of allylated D-mannose (1a), allylated L-mannose (1b), propargylated D-mannose (2), and the hydrogenated congener of 1a (3).

hydrogen bonded molecular packing in the crystal lattice which is formed by spontaneous aggregation from water solution. This seemingly unexpected, self-assembling property was proposed to originate from the highly ordered linear minimum energy conformation of the molecule both in solid state as well as in solution. ${ }^{13}$

In this paper, we have further studied the unusual selfassembling behavior of the mannose derived polyols and report here a thorough investigation on the solid state properties of compound 1a in admixture with its L-mannose derived enantiomer $\mathbf{1 b}$ (Figure 3) by combinations of crystallographic and NMR-spectroscopic techniques with thermal analysis. In addition, we present here the synthesis and characterization of the propargylated and hydrogenated analogues of 1a. Both of these compounds 2 and 3 (Figure 3) display aggregation behavior similar to their allylated congener. Along with structural characterization of the prepared substances, this study also sheds light on the rich polymorphism of compound $\mathbf{1 a}$ and the corresponding racemate (hereafter called $\mathbf{1}$ ), as perceived by combined DSC, PXRD, and solid state NMR analyses.

\section{EXPERIMENTAL SECTION}

General Remarks. D-Mannose was obtained from Danisco and Lmannose from Carbosynth. All other chemicals and solvents were purchased from Sigma-Aldrich and were used without further purification. HRMS were recorded with a Bruker Daltonics microToF instrument in positive mode using ESI-ionization. Optical rotations were recorded with a PerkinElmer 241 polarimeter equipped with a Na-lamp $(598 \mathrm{~nm})$.

NMR Spectroscopy. Solution state NMR spectra were recorded with a Bruker Avance-III HD $500 \mathrm{MHz}$ spectrometer equipped with a Bruker SmartProbe. PERCH software ${ }^{14}$ with spin simulation/iteration techniques was used for further analysis of the ${ }^{1} \mathrm{H}$ NMR spectra and for determining the $J$-coupling constants. CP MAS ${ }^{13} \mathrm{C}$ NMR spectra were obtained with a Bruker AVANCE-III HD $400 \mathrm{MHz}$ spectrometer. The powdered samples were spun at a $14 \mathrm{kHz}$ spin rate in a Bruker ${ }^{1} \mathrm{H}$ broadband double-resonance $4 \mathrm{~mm}$ CP MAS probe. The proton $90^{\circ}$ high-power pulse was $2.9 \mu$ s and contact time 2 ms. The recovery delay time was set to 240 , and 50 scans were accumulated in order to obtain satisfactory signal-to-noise ratio.

DSC Analysis. Thermal transitions of the samples were measured using a power compensation type PerkinElmer 8500 series differential scanning calorimeter. All heating/cooling scans were carried out under nitrogen atmosphere (flow rate $50 \mathrm{~mL} / \mathrm{min}$ ) using $50 \mu \mathrm{L}$ aluminum pans sealed by $30 \mu \mathrm{L}$ aluminum pans with pinholes (effective volume $20 \mu \mathrm{L}$ ). Temperature calibration was performed with two standard materials (indium and zinc) and the energy calibration by an indium standard. Each sample was typically heated and cooled twice or thrice from 25 to $210^{\circ} \mathrm{C}$ with a heating/cooling rate of $10^{\circ} \mathrm{C} / \mathrm{min}$. Due to the overlap of some transitions, the melting temperatures are reported as the peak maxima of the endothermic peak. The sample mass varied from 1.5 to $3 \mathrm{mg}$.

Calculations. For predicting the solid-liquid equilibria of the system, the simplified Schröder-van Laar (eq 1) and Prigogine-Defay (eq 2) equations were used, where $\Delta H_{R a c}^{f}$ and $\Delta H_{E n}^{f}$ are the enthalpies of fusion for the racemate and pure enantiomer, respectively, $T_{R a c}^{f}$ and $T_{E n}^{f}$ represent the corresponding melting temperatures, $R$ is the gas constant, and $x$ is the mole fraction of the more abundant enantiomer of the mixture. ${ }^{1}$ Due to occasional overlap of peaks in the DSC scans, 
peak maximum values of the melting transitions were used for the calculations.

$$
\begin{aligned}
& \ln x=\frac{\Delta H_{E n}^{f}}{R}\left(\frac{1}{T_{E n}^{f}}-\frac{1}{T}\right) \\
& \ln 4 x(1-x)=\frac{2 \Delta H_{R a c}^{f}}{R}\left(\frac{1}{T_{R a c}^{f}}-\frac{1}{T}\right)
\end{aligned}
$$

Hot Stage Microscopy. The optical microscope images were obtained with an OLYMPUS BX51 stereo microscope (with magnifications of 25-500 and polarization lenses) equipped with a Linkam LTS 420E temperature controlled microscope stage, a LN95LTS liquid $\mathrm{N}_{2}$ cooling unit, an OLYMPUS DP-26 high-resolution color CCD-camera, and OLYMPUS Stream image analysis software. Temperature calibration of the stage was made using an indium standard. A small amount of sample $(\sim 1 \mathrm{mg})$ was prepared on a standard microscope slide by placing a thin cover glass slide on top of a thin sample layer. Sample dependent heating/cooling rates were used (typically $1-10{ }^{\circ} \mathrm{C} / \mathrm{min}$ ) in order to observe the thermal events indicated by the DSC scans.

PXRD Analysis. The powder X-ray diffraction data was obtained with a PANalytical X'Pert PRO diffractometer in Bragg-Brentano geometry using $\mathrm{Cu} \mathrm{K} \alpha_{1}$ radiation (1.5406 $\AA$ with $45 \mathrm{kV}, 40 \mathrm{~mA}$ power settings and Johansson type monochromator). Each sample was lightly ground in a mortar and set on a reflection-free silicon-made plate using petrolatum jelly as an adhesive. The data was recorded from a spinning sample with an $\mathrm{X}^{\prime}$ Celerator detector using continuous scanning mode in the $2 \theta$ range of $3-70^{\circ}$ with a step size of $0.017^{\circ}$ and counting times of $60 \mathrm{~s}$ per step. Diffraction data were processed with the program PANalytical HighScore Plus (v. 4.6).

Single Crystal X-ray Diffraction. An Agilent Supernova $(\mathrm{Cu} / \mathrm{Mo}$ dual hi-flux microfocus sources) diffractometer was used to record the data at $-153,-150$, or $20^{\circ} \mathrm{C}$ using $\mathrm{Cu} \mathrm{K}_{\alpha}$ radiation $(\lambda=1.54184 \AA)$. For compound 1 two data collections were made, one at $-153^{\circ} \mathrm{C}$ and and one at room temperature. The structure model determined from the latter data set was used to calculate the simulated pattern used in powder X-ray diffraction analyses, in the case when structural consistency between bulk powder and the single crystal was evaluated. Data collection and reduction, as well as analytical numeric absorption corrections using multifaceted crystal models, were all made using the program CrysAlisPro (v. 1.171.38.46). ${ }^{15}$ Structures were solved by direct methods using SHELXS ${ }^{16}$ and were refined using SHELXL-97 ${ }^{16}$ both implemented in the program $\operatorname{OLEX}^{2}$ (v. 1.2.9). ${ }^{17}$ All nonhydrogen atoms were refined anisotropically whereas all $\mathrm{C}-\mathrm{H}$ and the $\mathrm{O}-\mathrm{H}$ hydrogen atoms in the structure of the racemate were refined as riding atoms with $U_{\text {iso }}$ parameters $1.2-1.5$ times their host atoms. The $\mathrm{O}-\mathrm{H}$ hydrogen atoms in the structure of compound 2 were located from the electron density map and refined isotropically without geometrical or $U_{\text {iso }}$ restraints.

Synthesis. Compound 1a (allylated D-mannose) was prepared as described previously ${ }^{18,19}$ and purified by recrystallization from distilled water in order to avoid cocrystallization of sodium bromide residues observed to contaminate the samples crystallized from ethanol. Isolated yields were similar to those reported earlier. ${ }^{13,19}$

$(2 S, 3 S, 4 S, 5 S, 6 R)-N o n-8-e n e-1,2,3,4,5,6$-hexol (1b). Compound $\mathbf{1 b}$ (allylated L-mannose) was prepared from L-mannose following a similar procedure as for 1a. ${ }^{19}$ White solid; $\mathrm{mp} 195-196{ }^{\circ} \mathrm{C}$ (equal to 1a); $[\alpha]_{\mathrm{D}}=+3.1^{\circ}\left(c=0.01 \mathrm{~g} / \mathrm{mL}, \mathrm{H}_{2} \mathrm{O}\right)$. NMR data is found in ESI.

$(2 R, 3 R, 4 R, 5 R, 6 S)$-Non-8-yne-1,2,3,4,5,6-hexol (2). Propargylated Dmannose (2) was synthesized by Grignard-reaction of an earlier described isopropylidene protected lactone ${ }^{20,21}$ followed by deprotection with acetic acid. $(2 R, 3 R, 4 R, 5 R, 6 S)-1,2: 4,5$-Di-O-isopropylidene-non-8-yne-1,2,3,4,5,6-hexol ( $1 \mathrm{~g}, 3.3 \mathrm{mmol})$ was suspended in an $80 \%$ acetic acid/water mixture $(50 \mathrm{~mL})$. The reaction mixture was stirred at $80{ }^{\circ} \mathrm{C}$ for $6 \mathrm{~h}$ and concentrated in vacuo, and the product was crystallized from distilled water to provide $530 \mathrm{mg}(72 \%)$ of $\mathbf{2}$ as a white powder. Mp 211-212 ${ }^{\circ} \mathrm{C} ;[\alpha]_{\mathrm{D}}=+2.5^{\circ}(c=0.01 \mathrm{~g} / \mathrm{mL}$,
DMSO). HRMS calcd for $\mathrm{C}_{9} \mathrm{H}_{16} \mathrm{O}_{6} \mathrm{Na}[\mathrm{M}+\mathrm{Na}]^{+}$243.0839, found 243.0865. NMR data is found in ESI.

(2R,3R,4R,5R,6S)-Nonan-1,2,3,4,5,6-hexol (3). Compound 1a (320 $\mathrm{mg}, 1.4 \mathrm{mmol})$ was suspended in dry $\mathrm{MeOH}(30 \mathrm{~mL}) . \mathrm{Pd} / \mathrm{C}(10 \%, 50$ $\mathrm{mg}, 3 \mathrm{~mol} \%$ ) was added under stirring. The reactor was pressurized with hydrogen ( $3 \mathrm{~atm})$, and the mixture was stirred overnight. Distilled water $(250 \mathrm{~mL})$ was added and the resulting mixture was filtered through Celite. The filtrate was concentrated in vacuo, and the product was recrystallized from distilled water to yield $178 \mathrm{mg}(55 \%)$ of 3 as a white powder. White solid; mp 207-208 ${ }^{\circ} \mathrm{C}$; $[\alpha]_{\mathrm{D}}=-7.8^{\circ}(\mathrm{c}$ $=0.01 \mathrm{~g} / \mathrm{mL}$, DMSO). HRMS calcd for $\mathrm{C}_{9} \mathrm{H}_{20} \mathrm{O}_{6} \mathrm{Na}[\mathrm{M}+\mathrm{Na}]^{+}$ 247.1152, found 247.1150. NMR data is found in ESI.

Preparation of Mixtures of $1 \mathrm{a}$ and $\mathbf{1 b}$ for Thermal Analysis. Enantiomers $\mathbf{1 a}$ and $\mathbf{1 b}$ were weighed in desired proportions followed by thorough mixing in a mortar. The mixtures were subsequently dissolved in distilled water $(20 \mathrm{mg} / \mathrm{mL})$ by gentle heating under stirring, or ethanol $(10 \mathrm{mg} / \mathrm{mL})$ by reflux until complete dissolution. The aqueous solutions were allowed to cool down to room temperature and were then kept at $6{ }^{\circ} \mathrm{C}$ for $24-48 \mathrm{~h}$. The solids were separated from the liquid through centrifugation and decantation, followed by freeze-drying of the crystals. The ethanol solutions were allowed to cool down to room temperature and left overnight for complete precipitation. The solid phase was separated through filtration and was freeze-dried before further analysis.

Preparation of Aggregates. Bulk powders of enantiomers 1a and $\mathbf{l b}$, or compounds 2 and 3 (20 mg in $1 \mathrm{~mL}$ distilled water or 20, 40, 60 , 80 , or $100 \mathrm{mg}$ in $1 \mathrm{~mL}$ DMSO), were dissolved by gentle heating and stirring of the sample. The resulting solution was allowed to cool down to room temperature, after which the sample was stirred vigorously at $1200 \mathrm{rpm}$. In the case of aggregate formation, the samples were centrifuged, decanted, and subsequently freeze-dried.

\section{RESULTS AND DISCUSSION}

Compound Preparation and Aggregation Behavior. The predominant diastereomer $\mathbf{1 a}$ formed in the metalmediated allylation of D-mannose has previously been isolated by chromatography ${ }^{18}$ or by recrystallization from ethanol. ${ }^{19}$ In this work, however, we found that recrystallization from ethanol may result in cocrystallization of minor sodium bromide impurities. Therefore, we investigated whether compound 1a could also be recrystallized selectively from water. Crystallization attempts from water proved successful and yielded 1a in analogous quantities as previously reported ${ }^{19}$ but free of $\mathrm{NaBr}$ as verified by PXRD analysis.

For synthesis of compound 2, several attempts were made by applying a direct metal-mediated propargylation of mannose. Unfortunately, this strategy was unsuccessful as the conversions were typically very low $(<10 \%)$ and the isolation processes proved tedious. In addition, rearrangement of the triple bond to the corresponding allene further complicated the direct Barbiertype synthetic pathway toward this compound. An alternative route for propargylation of mannose has been described by Kanai. $^{22}$ The reported method, however, involves the use of expensive chiral ligands. Here, compound 2 was prepared in good yield based on Grignard-reaction of an isopropylidene protected lactone described earlier by $\mathrm{Crich},{ }^{20}$ followed by deprotection with acetic acid. The hydrogenated congener 3 was prepared from 1 a with $\mathrm{H}_{2}$ over $\mathrm{Pd} / \mathrm{C}$. The racemic mixture of allylated mannoses (1) as well as the propargylated and hydrogenated analogues were all observed to show aggregation behavior similar to 1a when dissolved in water at $0.09 \mathrm{M}$ concentrations and stirred vigorously. The aggregation occurred after approximately $30 \mathrm{~min}$ in all cases and was visually identical to the aggregation of 1 a. However, none of the compounds exhibited aggregation in the aprotic polar solvent DMSO at concentrations between 0.09 and $0.45 \mathrm{mM}$. 
Conformational Analysis by Solution State NMR Spectroscopy. Conformational properties of various carbohydrate-derived polyols have been studied earlier in detail by solution state NMR spectroscopy. ${ }^{23-26}$ A more universal model for conformational analysis of acyclic structures has been developed based on $J$-coupling constants. For protons in gauche orientation the vicinal $J_{\mathrm{H}, \mathrm{H}}$-coupling is typically less than $3 \mathrm{~Hz}$, while for protons in anti orientation the coupling varies between 7 and $10 \mathrm{~Hz}^{27}$ Consequently, in a planar, linear zigzag conformation of a polyol the vicinal $J$-coupling should be either small $(<3 \mathrm{~Hz})$ or large $(7-10 \mathrm{~Hz})$, as the neighboring protons are positioned either in a gauche or anti orientation. Mediumsized vicinal $J$-coupling constants $(3-7 \mathrm{~Hz})$ would in turn indicate that the molecule adopts a nonlinear or nonplanar conformation in solution. In our previous work, the J-coupling constants of $1 \mathrm{a}$ (entry 1 , Table 1 ) in $\mathrm{D}_{2} \mathrm{O}$ fully corresponded to

Table 1. ${ }^{3} J_{H, H}$ Coupling Constants $(\mathrm{Hz})$ for Compounds 1a, 2 , and 3 in $\mathrm{D}_{2} \mathrm{O}$ and Deuterated DMSO

\begin{tabular}{|c|c|c|c|c|c|c|}
\hline Entry & Structure & Solvent & $J_{\mathrm{H} 2, \mathrm{H} 3}$ & $J_{\mathrm{H} 3, \mathrm{H} 4}$ & $J_{\mathrm{H} 4, \mathrm{H} 5}$ & $J_{\mathrm{H} 5, \mathrm{H} 6}$ \\
\hline 1 & $\underset{\mathrm{OH}}{\mathrm{OH}}$ & $\mathrm{D}_{2} \mathrm{O}^{\mathrm{a}}$ & 8.9 & 1.1 & 9.3 & 1.5 \\
\hline 2 & $\overline{\mathrm{O}} \mathrm{H} \stackrel{\mathrm{O} H}{ }$ & DMSO & 8.3 & $<0.5$ & 9.3 & 1.6 \\
\hline 3 & $\underset{\mathrm{OH}}{\mathrm{OH}} \mathrm{O}^{9}$ & $\mathrm{D}_{2} \mathrm{O}$ & 8.9 & 1.1 & 9.5 & 1.5 \\
\hline 4 & $\stackrel{\overline{\mathrm{O}}}{\mathrm{H}} \stackrel{\mathrm{O}}{\mathrm{O}}$ & DMSO & 8.3 & 1.0 & 9.3 & 1.5 \\
\hline 5 & $\stackrel{\mathrm{OH}}{\mathrm{OH}}{ }_{8}$ & $\mathrm{D}_{2} \mathrm{O}$ & 8.9 & 1.1 & 9.3 & 1.5 \\
\hline 6 & $\stackrel{\overline{\mathrm{O}}}{\mathrm{H}}{ }_{\mathrm{O}}^{1} \mathrm{H}^{7}$ & DMSO & 8.4 & 1.1 & 9.2 & 1.7 \\
\hline
\end{tabular}

${ }^{a}$ Data taken from ref 13 .

a linear, planar zigzag conformation. ${ }^{13}$ Here, similar solution state ${ }^{1} \mathrm{H}$ NMR experiments were performed with compounds 2 and 3. For both compounds the $J$-coupling constants are in perfect agreement with those reported earlier for 1a, indicating that also $\mathbf{2}$ and $\mathbf{3}$ adopt linear minimum energy conformations in aqueous solution (Table 1).

The absence of aggregation of these compounds in DMSO motivated us to investigate if their linear conformations are solvent-dependent. Thus, the NMR spectroscopic analysis of compounds 1a, 2, and 3 was repeated in deuterated DMSO. All compounds showed similar $J$-coupling constants (Table 1) in both DMSO and in $\mathrm{D}_{2} \mathrm{O}$, indicating that water as the solvent is not a prerequisite for the linear conformations of these mannose derivatives in solution.

Determination of Binary Melting Point Diagram. Allylated mannose samples in different enantiomeric ratios $0.5<X_{\mathrm{D}}<1.0$, where $X_{\mathrm{D}}$ represents the mass fraction of allylated D-mannose, were crystallized from water and analyzed by DSC in order to construct a binary melting point diagram, from which the distinction between a true racemate, conglomerate, and solid solution type crystallization from racemic solution can be made. The pure enantiomer $1 \mathbf{a}\left(X_{\mathrm{D}}=\right.$ 1.0) exhibits a single melting peak at $195.8^{\circ} \mathrm{C}$ (Figure 4). The binary mixtures $\left(0.9 \leq X_{\mathrm{D}} \geq 0.6\right)$ show two endothermic peaks of which one is always located at approximately $191{ }^{\circ} \mathrm{C}$, consistent with eutectic melting. The second peak shifts depending on the enantiomeric ratio, first to lower temperatures, but with the ratio approaching $X_{\mathrm{D}}=0.5$, the melting peak shifts clearly to a higher temperature than for the pure

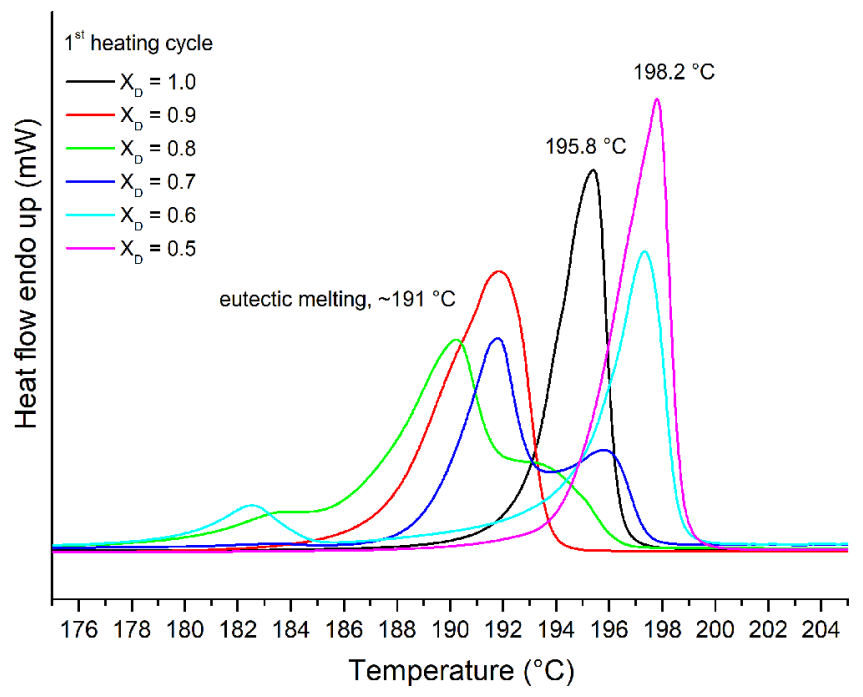

Figure 4. DSC curves of the mixed enantiomers $(\mathbf{1} \mathbf{a}+\mathbf{1 b})$ heated with a rate of $10{ }^{\circ} \mathrm{C} / \mathrm{min} . X_{\mathrm{D}}$ indicates the mass fraction of allylated Dmannose in the corresponding sample.

enantiomer. Finally, the sample having a $1: 1$ ratio of enantiomeric pairs shows a single melting transition at $198{ }^{\circ} \mathrm{C}$.

The measured DSC data indicates that the racemic mixture of allylated mannose crystallizes from water as a true racemate (1) and not as a conglomerate or a solid solution. This is further evidenced by powder diffraction analysis, where the PXRD patterns corresponding to the pure enantiomer and the racemic mixture are clearly different (Figure 5). The formation

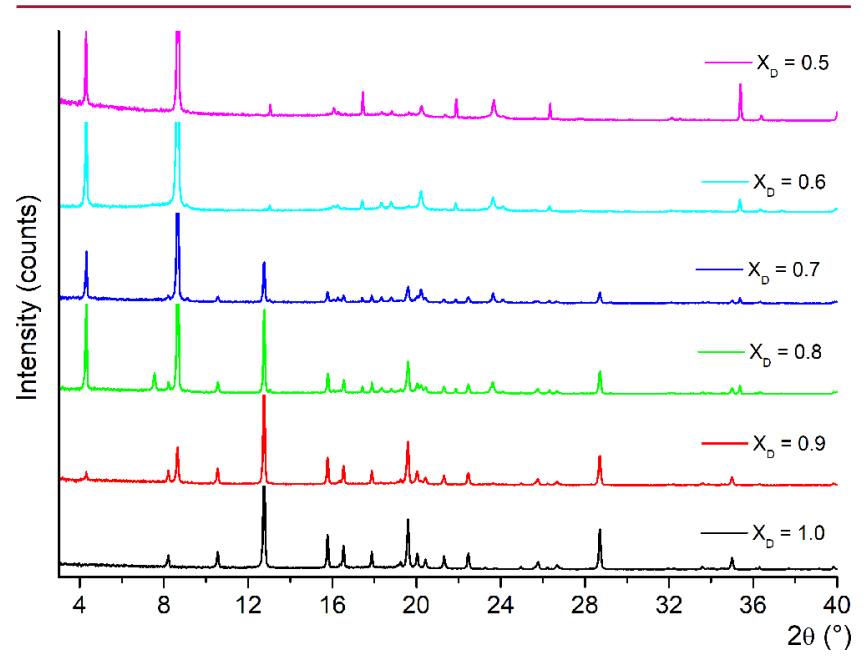

Figure 5. PXRD patterns of allylated D- and L-mannose $\mathbf{1 a}$ and $\mathbf{1 b}$, recrystallization products from water; $X_{\mathrm{D}}$ stands for the mass fraction of $1 \mathrm{a}$ in the enantiomeric mixture. For clarity, the patterns are partially cut off from the top due to the strong intensities of some Bragg peaks caused by the preferred orientation of the crystals.

of a racemic compound is already observed at the ratio of $X_{\mathrm{D}}=$ 0.9 , as a small amount of racemate crystals are formed along with crystallization of the excess enantiomer. This can be seen as new diffraction peaks in the PXRD pattern, e.g. at $4.3^{\circ}$ and $8.6^{\circ} 2 \theta$ which are the strongest Bragg peaks of the racemate (Figure 5). With an increase in mass fraction of the allylated Lmannose $\mathbf{1 b}$, more characteristic peaks of the racemic compound appear at $13.1^{\circ}, 17.4^{\circ}$, and $21.9^{\circ} 2 \theta$. At $X_{\mathrm{D}}=0.7$ the racemic compound $\mathbf{1}$ is already the major component, and 
with $X_{\mathrm{D}}=0.5$ only diffraction peaks characteristic for the racemate are visible in the pattern.

Further evidence for formation of a true racemate is obtained from the BMPD. By solving the Prigogine-Defay and Schröder-van Laar eqs (Table 2 and Figure 6), liquidus lines

Table 2. Summary of the Thermal Properties of 1, 1a, 2, and 3

\begin{tabular}{|c|c|c|c|c|}
\hline Polymorph & Formation & $T_{s s}\left({ }^{\circ} \mathrm{C}\right)^{a}$ & $T_{m}\left({ }^{\circ} \mathrm{C}\right)^{b}$ & $\underset{\mathrm{kJ} / \mathrm{mol}}{\Delta H}$ \\
\hline 1-I & $\begin{array}{l}\text { Cryst. or aggregation from } \\
\text { water }\end{array}$ & & 198.0 & 72.02 \\
\hline 1-II & Cryst. from ethanol & & 196.3 & 70.86 \\
\hline 1-III & Cryst. from the melt & & 195.5 & 62.68 \\
\hline 1a-I & $\begin{array}{l}\text { Cryst. or aggregation from } \\
\text { water }\end{array}$ & & 195.8 & 67.28 \\
\hline 1a-II & $\begin{array}{l}\text { Cryst. from ethanol and } \\
\text { the melt }\end{array}$ & $\begin{array}{l}150-152 \\
(\text { II } \rightarrow \overrightarrow{\text { IIb })}\end{array}$ & $\begin{array}{l}189.0 \\
(\mathbf{I I b})\end{array}$ & 57.19 \\
\hline 2 & $\begin{array}{l}\text { Cryst. from water and the } \\
\text { melt }\end{array}$ & & 212.8 & 74.32 \\
\hline 3 & $\begin{array}{l}\text { Cryst. from water and the } \\
\text { melt }\end{array}$ & & 208.4 & 69.55 \\
\hline
\end{tabular}

${ }^{a}$ Polymorph 1a-II shows solid-state transition with average transition enthalpy of $\Delta H=2.9 \mathrm{~kJ} / \mathrm{mol}$. Transition temperature reported as peak maximum. ${ }^{b}$ Reported as peak maximum.

can be drawn which clearly support the crystallization behavior of a racemic compound. The eutectic melting point for the racemic system is predicted to be at $190.8{ }^{\circ} \mathrm{C}$ with molar ratio of $X_{\mathrm{D}}=0.83$. The BMPD was also constructed from DSC data of the second heating steps, thus corresponding to melting of the crystalline phases that formed under cooling of the melt (Figure 6). As suggested by the diagram, the melt crystallized structure form is also a racemic compound, for which the eutectic melting point is predicted at $184.5^{\circ} \mathrm{C}$ with ratio $X_{\mathrm{D}}=$ 0.86 . For both systems, the eutectic points were experimentally confirmed by preparing DSC samples with the predicted ratios of enantiomers. In both cases, DSC scans (ESI Figure S2) showed single sharp melting transitions, and the determined melting points (190.3 and $184.7^{\circ} \mathrm{C}$, respectively) agreed well with the predicted temperatures.

Polymorphism Analysis. The polymorphic behavior of the pure enantiomer 1a was briefly addressed in our earlier work. ${ }^{13}$ It was concluded that one polymorphic form of allylated Dmannose (1a-I) can be obtained by recrystallization or aggregation from water, whereas a second polymorph (1a-II) crystallizes from ethanol. This prompted us to investigate whether similar polymorphism is inherited by the racemate when crystallized or aggregated from ethanol or water. As shown by the DSC data (Figure 7, top), the racemate sample

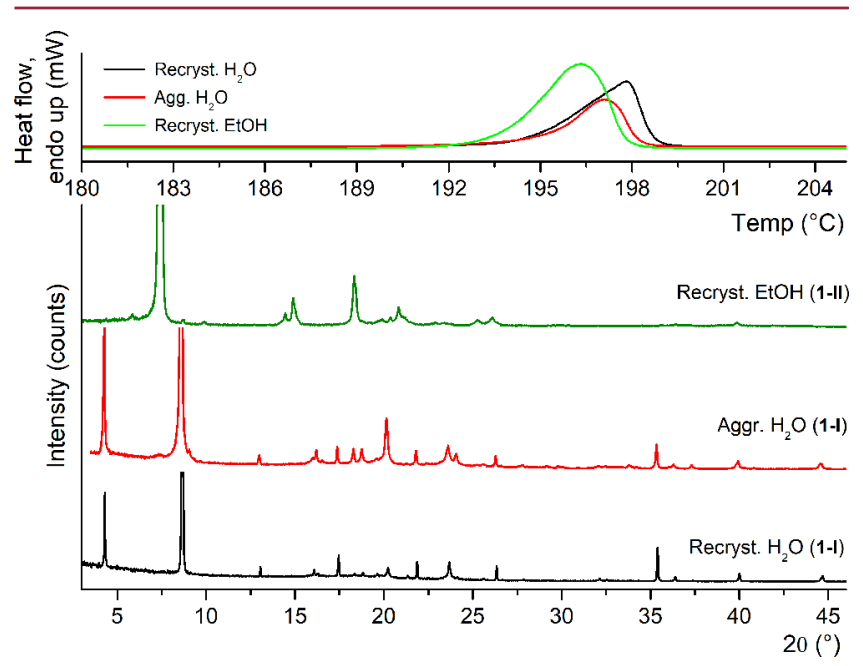

Figure 7. DSC curves (top) and the corresponding XRD patterns of racemate 1 recrystallized or aggregated from water and recrystallized from ethanol. The patterns are partially cut off from the top for clarity.

crystallized from ethanol melts at $196.3{ }^{\circ} \mathrm{C}(\Delta H=70.86 \mathrm{~kJ} /$ $\mathrm{mol}$ ), while the aggregation or crystallization from water affords samples with melting peaks at $196.9^{\circ} \mathrm{C}(\Delta H=72.42 \mathrm{~kJ} / \mathrm{mol})$ and $197.8^{\circ} \mathrm{C}(\Delta H=72.02 \mathrm{~kJ} / \mathrm{mol})$, respectively. Based on the DSC data alone it is not possible to make a structural distinction between the samples with sufficient certainty, but examination of the corresponding PXRD patterns (Figure 7)
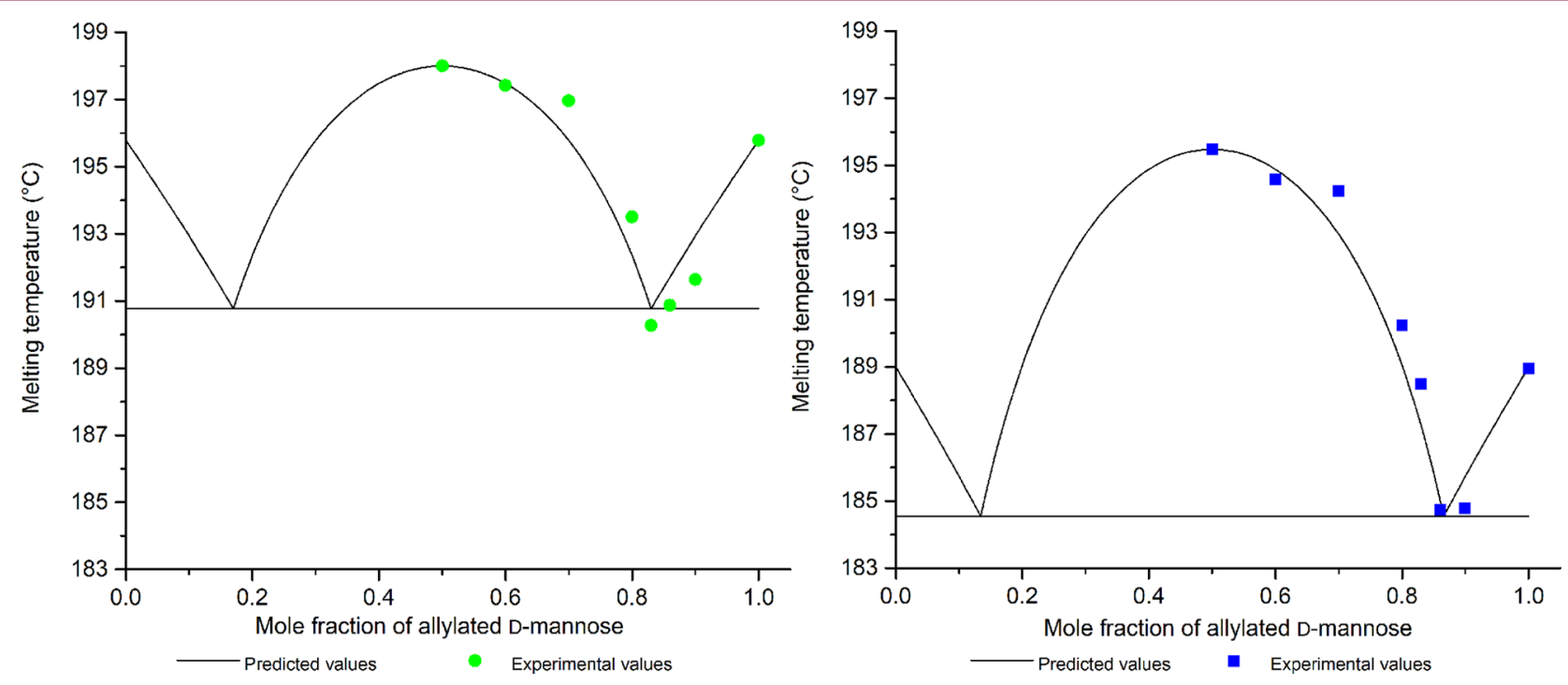

Figure 6. Binary melting point phase diagrams of enantiomeric mixtures of allylated mannose recrystallized from water (left) and from the melt (right). 
proved that the racemic mixture of allylated mannose crystallizes in two different forms. The first form (1-I) crystallizes and/or aggregates from water, whereas the second form (1-II) can be obtained by crystallization from ethanol. Hence, the racemate shows polymorphic behavior similar to the parent allylated D-mannose 1a (ESI Figure S3).

Thermal behavior of the racemic polymorphs was further investigated by running consecutive heating-cooling cycles by DSC. The results are summarized in Table 2. For the pure enantiomer 1a, concise DSC analyses were already reported in our previous study. ${ }^{13}$ For further insights into the polymorphism, some additional DSC scans were made with 1a also in the present work (see ESI). Both racemate forms 1-I and 1II show single melting peaks at 198 and $196.3{ }^{\circ} \mathrm{C}$, respectively (Figure 8, top). Interestingly, in the following cooling steps,

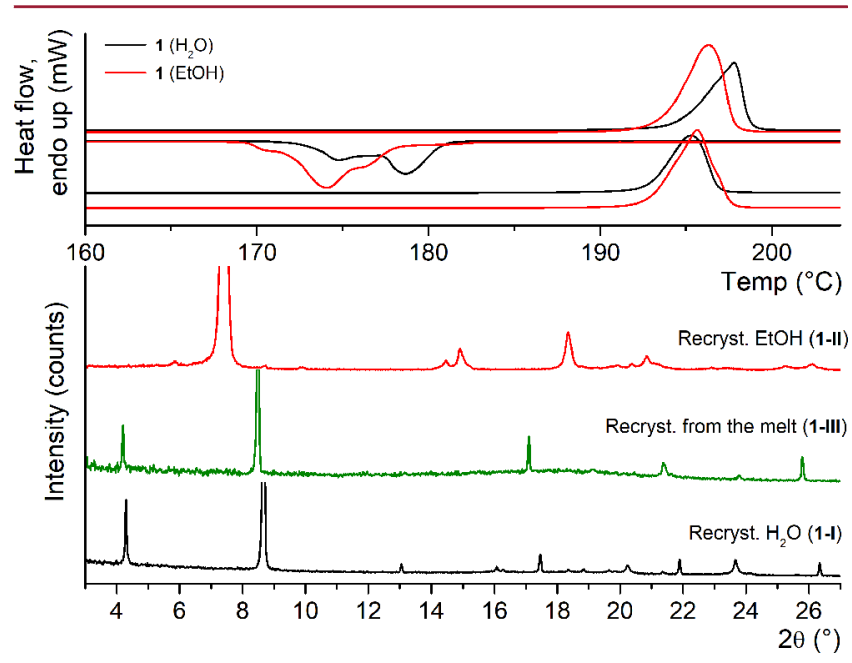

Figure 8. DSC curves and the corresponding XRD patterns of the racemate polymorphs crystallized from water (1-I), ethanol (1-II), and the melt (1-III).

melts of both substances crystallize between $180-160{ }^{\circ} \mathrm{C}$, and in the following heating steps only a single melting peak is observed in both DSC curves, but now at $195.5{ }^{\circ} \mathrm{C}(\Delta H=$ $62.73 \mathrm{~kJ} / \mathrm{mol}$ ). Further PXRD analysis showed that a third polymorph (1-III) forms upon crystallization of the racemate from the melt. The pattern of the third polymorph 1-III (Figure 8) is perceptibly different from 1-II, but it shares significant similarities with the polymorph 1-I. Closer inspection reveals modest movement of most of the peaks in the pattern toward lower $2 \theta$ angles. Furthermore, some new peaks appear and a few peaks characteristic of polymorph 1-I disappear. As the differences are only minor, it is expected that the crystal lattice of the third polymorph strongly resembles that of form 1-I. Unfortunately, further structural analysis of polymorph 1-III could not be performed, as the small sample amounts available were not sufficient for obtaining a high quality XRD required for powder structure determination. Here, compounds 2 and 3 were also examined by DSC. Both compounds showed only one endothermic transition upon consecutive heating-cooling cycles, consistent with the presence of a single polymorph only for these compounds (Table 2).

The thermodynamic rules developed by $\operatorname{Tamman}^{28}$ and later extended by Ramberger, Yu, Grunenberg, and others ${ }^{29,30}$ can be used as guidelines to estimate the relative thermodynamic stability between the racemic forms. According to the heat of fusion rule, polymorphic pairs are enantiotropically related if the lower melting form has the higher heat of fusion. Otherwise the relationship is monotropic. Similarly, polymorphs are enantiotropically related if the endothermic transition from a low melting form to a high melting form is observed; otherwise, the relation again is monotropic. ${ }^{29,30}$ Thus, the determined melting points and enthalpies of fusions (Table 2) of the racemic forms 1-I, 1-II, and 1-III suggest that all three forms are monotropically related.

Hot Stage Microscopy. Hot stage microscopy (HSM) combines microscopy with thermal analysis. With this technique, thermal events observed by DSC or TGA, as well as the morphology of compounds can be visualized. Figure 9
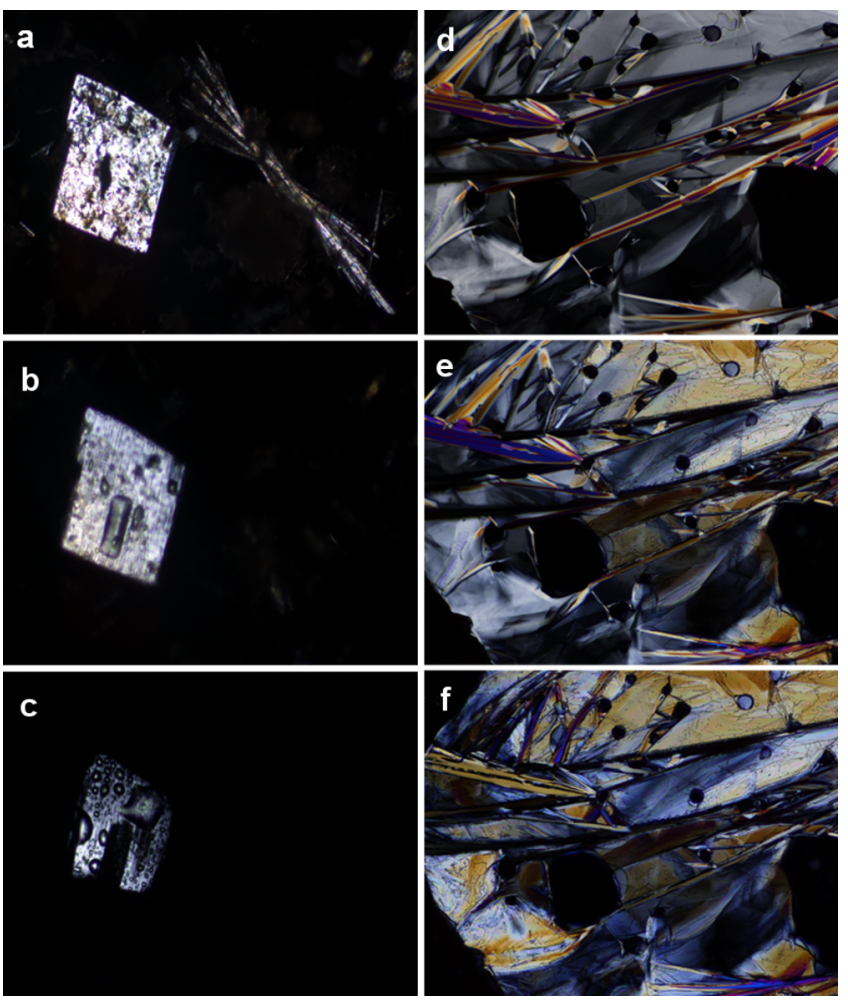

Figure 9. Hot stage microscopy images of racemate $\mathbf{1}$ (left crystal) and enantiomer 1a (right crystal) under polarized light, heated with the rate $10{ }^{\circ} \mathrm{C} / \mathrm{min}$ at $25{ }^{\circ} \mathrm{C}(\mathrm{a}), 196{ }^{\circ} \mathrm{C}(\mathrm{b})$, and $199{ }^{\circ} \mathrm{C}(\mathrm{c})$; Hot stage microscopy images of $1 \mathrm{a}$ on cooling $10^{\circ} \mathrm{C} / \mathrm{min}$, crystallized at $179^{\circ} \mathrm{C}$ (d), under solid-state phase transition at $145^{\circ} \mathrm{C}(\mathrm{e})$, and at $139^{\circ} \mathrm{C}$ (f).

shows hot stage microscopy images of the morphology of racemic and enantiopure allylated mannose, as well as texture changes in the enantiopure compound under the solid-state phase transition temperature. Microscopic observations of the bulk powders revealed that the crystal shapes of the pure enantiomer (1a-I) and the racemate 1-I are significantly different. As seen from the images (Figure 9a), 1a-I crystallizes as needle-like crystals which form loose bundles, whereas the racemate forms thin, platelike crystals. Upon heating, as shown by hot stage microscopy, the enantiomerically pure crystals melt at a slightly lower temperature than the racemate crystals (196 vs $199^{\circ} \mathrm{C}$, respectively, Figure $9 \mathrm{~b}-\mathrm{c}$ ), consistent with the DSC data. Also the solid-solid phase transition of 1a observed by DSC could be verified with HSM. Figure 9d shows the crystallization texture of the pure enantiomer 1a taken at 179 ${ }^{\circ} \mathrm{C}$. Images $9 \mathrm{e}-\mathrm{f}$ then show how the texture and the light transmission characteristics of the crystalline film clearly change 
due to the structural changes when the sample is cooled below the solid-state phase transition temperature $\left(150{ }^{\circ} \mathrm{C}\right)$.

Single Crystal X-ray Diffraction. Next, the molecular conformation and intermolecular packing of racemic allylated mannose (polymorph 1-I) and propargylated D-mannose (2) were analyzed by single crystal X-ray diffraction. For compound 1-I the analyses were conducted using two different measuring temperatures, as described in the experimental section. The determined unit cell parameters of the racemate 1-I crystals $\left(-150{ }^{\circ} \mathrm{C}\right)$ exhibit significant resemblance to those reported previously for $1 \mathbf{a}-\mathbf{I}^{13}$ (Table 3$)$. However, in contrast to the

Table 3. Crystallographic Data for Compounds 1-I and 2 (full listing in SI Table S1)

\begin{tabular}{llll} 
Crystal structure & $\mathbf{1 - I}$ & $\mathbf{1 - I}-\mathrm{RT}$ & $\mathbf{2}$ \\
Crystal system & Triclinic & Triclinic & Monoclinic \\
Space group & $P \overline{1}$ & $P \overline{1}$ & $P 2_{1}$ \\
$a / \AA$ & $5.5616(4)$ & $5.5779(4)$ & $5.0042(4)$ \\
$b / \AA$ & $9.5579(6)$ & $9.6352(6)$ & $4.9642(3)$ \\
$c / \AA$ & $20.015(3)$ & $20.221(2)$ & $20.9253(13)$ \\
$\alpha /$ deg & $92.650(9)$ & $90.713(7)$ & 90 \\
$\beta /$ deg & $91.990(9)$ & $92.120(7)$ & $93.614(6)$ \\
$\gamma /$ deg & $92.563(6)$ & $92.692(6)$ & 90 \\
Volume/A & $1061.0(2)$ & $1084.69(16)$ & $518.79(6)$ \\
$Z$ & 4 & 4 & 2 \\
$\rho_{\text {calc }} / g / \mathrm{cm}^{3}$ & 1.391 & 1.361 & 1.41 \\
Goodness-of-fit on $\mathrm{F}^{2}$ & 1.049 & 1.02 & 1.059 \\
$\mathrm{R}_{\mathrm{w}}$ and $\mathrm{R}_{\mathrm{wp}}$ & $\mathrm{R}_{1}=0.0890$ & $\mathrm{R}_{1}=0.0857$ & $\mathrm{R}_{1}=0.0334$ \\
{$[I \geq 2 \sigma(I)]$} & $\mathrm{wR}_{2}=0.2469$ & $\mathrm{wR}_{2}=0.2522$ & $\mathrm{wR}_{2}=0.0870$ \\
\hline
\end{tabular}

enantiopure D-mannose derivative, the structure of the racemate is centrosymmetric and can be solved and refined in the triclinic space group $P \overline{1}$. The asymmetric unit of $1-I$ consists of the two enantiomeric forms of the allylated mannose, both in linear conformation and residing within hydrogen bond interaction distance from each other (Figure 10).

In the racemic crystal, both individual enantiomers show disorder of their allylic tails over two positions (1:1 ratio), but not in the linear polyol backbones. The seemingly complete refinement scheme, however, overlooks some significant residual electron density that remains close to each of the 12 oxygen-carrying carbon atoms. A thorough analysis of the residual density, as well as the occupancy factors of the $\mathrm{O}$ atoms, suggests that the polyol backbones of the unique molecules in the asymmetric unit are disordered in a 9:1 ratio. Superimposing the opposite enantiomers in $10 \%$ occupancy on top of each of the two stereoisomers decreases the refined $R_{1}$ value by almost $3 \%$-units.

The diffraction data measured for $\mathbf{1 - I}$ at $20{ }^{\circ} \mathrm{C}$, solved by the corresponding structure model, exhibit the same triclinic crystal system with $P \overline{1}$ symmetry and similar unit cell parameters, taking the effects of thermal expansion into account (ESI, Figure S6 for 1-I-RT). A similar disorder model with the equal ratio of disordered enantiomers could also be used in the structure solution of the room temperature diffraction data, further supporting the veracity of the presented structure model. The solid state ordering of structure 1-I is dominated by $\mathrm{O}-\mathrm{H} \cdots \mathrm{O}$ hydrogen bond interactions, which cause propagation of the molecules into infinite arrays along the $a$ - and $b$-axes of the unit cell (Figure 10). Specifically, both stereoisomers 1a and $\mathbf{1 b}$ form hydrogen bonds to the enantiomer of the same handedness along the a-axis (ie. "LLLLLL" and "DDDDDD"), whereas arrays of enantiomers of alternating handedness are formed along the $b$-axis ("LDLDLD"). Consequently, twodimensional sheets consisting of both stereoisomers are formed in the crystallographic ab-plane. Notably, this packing scheme applies for both the major (90\%) and minor (10\%) disordered parts of racemate 1-I, as they differ only in the ordering sequence of the stereoisomers in the crystal lattice (i.e., "DLDLDL" vs "LDLDLD"). The hydrogen bonded layers are separated by the hydrophobic allyl groups on one side and the terminal carbons of the polyol framework on the other. Hence, the hydrophobicity, arising from the allyl functionality, seems to play a more significant role in dictating the solid state packing of the racemate compared to the pure enantiomer of the allylated D-mannose 1a. In the latter, the hydrogen bonding interactions propagate in three dimensions and segregation of the hydrophobic and hydrophilic parts of the molecules into their own layers is not observed.

In addition to the racemate 1 , crystallographic analysis of the propargylated D-mannose 2 was conducted. The structure was solved in a monoclinic crystal system and polar space group $P 2_{1}$ with the unit cell consisting of two molecules with $Z^{\prime}=1$. The intermolecular packing of compound $\mathbf{2}$ is dictated by $\mathrm{O}-\mathrm{H} \cdots \mathrm{O}$ hydrogen bonding interactions which generate two-molecule thick two-dimensional layers along the crystallographic $a b$ plane (Figure 11). The $\mathrm{O}-\mathrm{H} \cdots \mathrm{O}$ hydrogen bonds occur inside these layers with the propargyl groups of each molecule facing outward (cf. the one-molecule thick layer of the structure of the racemate 1 ) and toward the propargyl groups of adjacent layers. The intermolecular $\mathrm{C}-\mathrm{H} \cdots \pi$ distances between the calculated acetylenic $\mathrm{H}$ atoms and the propargyl groups of adjacent molecules are $2.82 \AA\left[\angle\left(\mathrm{C}-\mathrm{H} \cdots \mathrm{C}_{\text {propargyl }}\right)=143.8^{\circ}\right]$, suggesting
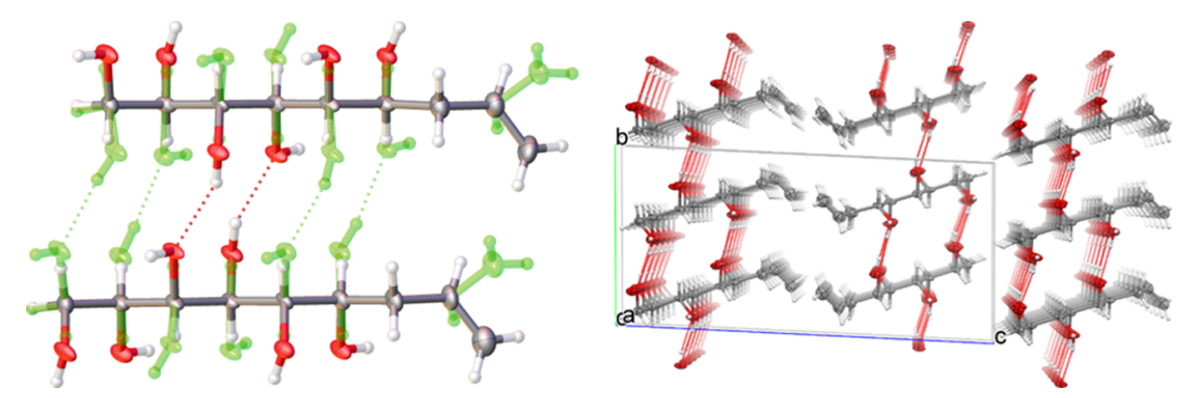

Figure 10. (a) Illustration of the asymmetric unit of the crystal structure of the racemate 1-I (for room temperature structure 1-I-RT, see ESI) showing enantiomeric disorder [major part (90\%) of the disordered $\mathrm{O}$ atoms are drawn in red and minor (10\%) in green] (left). The allyl groups are disordered in a 1:1 ratio; Presentation of the solid state ordering of 1-I viewed along the crystallographic $a$-axis with hydrogen bonding interactions highlighted in red (right). Thermal ellipsoids are presented at the $50 \%$ probability level. Letters a, b, and c represent the axes in the crystal lattice. 

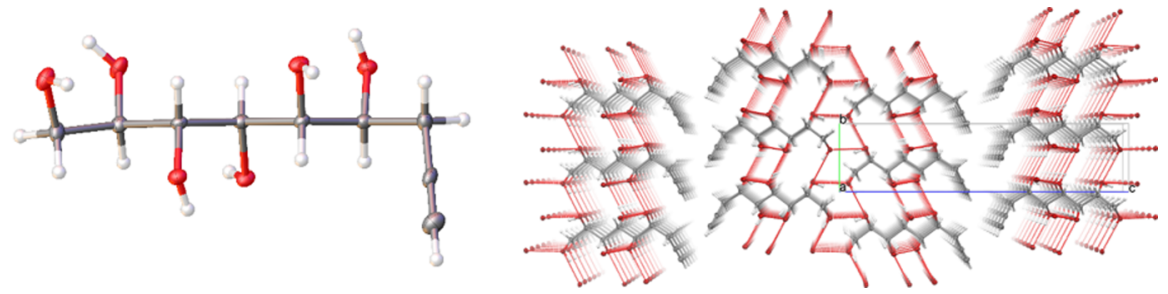

Figure 11. (a) Illustration of the asymmetric unit of the crystal structure of 2 (left). (b) Presentation of the solid state ordering of 2 viewed along the crystallographic $a$-axis with hydrogen bonding interactions highlighted in red (right). Thermal ellipsoids are presented at the $50 \%$ probability level.

that the hydrophobic layers are upheld by weak $\mathrm{C}-\mathrm{H} \cdots \pi$ interactions. The intermolecular propargyl interactions in $\mathbf{2}$ are perhaps one of the underlying reasons why the solid state structure of 2 , in contrast to the pure enantiomer 1a, shows segregation of the hydrophilic and hydrophobic parts of the molecule. The propargyl moiety also possesses a lesser degree of conformational freedom which may further promote the formation of the hydrophobic layer in the crystal structure. However, whereas the pure enantiomer of the allyl derivative 1a exhibits $\mathrm{O}-\mathrm{H} \cdots \mathrm{O}$ hydrogen bonding throughout the structure, hydrophobic/hydrophilic segregation occurs within the crystal structure of the racemate of allyl derivative 1 , where the hydrophobic allyl groups show weak $\mathrm{C}-\mathrm{H} \cdots \pi$ interactions (2.89 $\AA$ ). This demonstrates that the studied allyl and propargyl derivatives exhibit a delicate balance between the hydrophilic and hydrophobic interactions, with distinct implications to the solid state ordering of the molecules. In order to make further predictions on these effects, analysis of a more significant variety of different hydrophobic functionalities would be required.

For compound 3, several crystallization attempts were made in order to acquire crystals suitable for structure determination, but unfortunately only poorly diffracting crystals of insufficient quality were obtained.

Solid State NMR Spectroscopy. Both the racemic allylated mannose (polymorphs $\mathbf{1 - I}$ and 1-II) and the enantiomerically pure allylated D-mannose (polymorphs 1a-1 and 1a-II) were analyzed by CP MAS ${ }^{13} \mathrm{C}$ NMR spectroscopy. Chemical shifts of the signals from all polymorphs are summarized in Table 4. The signals have been assigned based

Table 4. Chemical Shifts of the CP MAS ${ }^{13} \mathrm{C}$ NMR Signals of 1 and 1a Polymorphs

\begin{tabular}{cccccc}
\multicolumn{7}{c}{${ }^{13} \mathrm{C}$ chemical shifts $(\mathrm{ppm})$} \\
\hline Polymorph & $\mathrm{C} 1$ & $\mathrm{C} 2-\mathrm{C} 6$ & $\mathrm{C} 7$ & $\mathrm{C} 8$ & $\mathrm{C} 9$ \\
1-I & 61.7 & $65-74$ & $36-40$ & $133-137$ & $115-120$ \\
1-II & 61.3 & $62-75$ & $35-40$ & $130-137$ & $113-121$ \\
1a-I & 62.1 & $65-75$ & 38.9 & 132.5 & 119.2 \\
1a-II & 60.3 & $64-72$ & 38.1 & 134.4 & 116.1 \\
\hline
\end{tabular}

on the corresponding solution state ${ }^{13} \mathrm{C}$ NMR spectra. For compounds able to form strong intermolecular hydrogen bonds, the delay time (D1) in the pulse sequence usually needs to be longer than for non-hydrogen bond forming compounds. ${ }^{12}$ Here, the delay time was optimized by running 50 scan experiments with D1 varying between 2 and $600 \mathrm{~s}$. At delay times longer than $240 \mathrm{~s}$, significant improvements in spectral quality were not observed. For these experiments, D1 was consequently set to $240 \mathrm{~s}$. Figure 12 shows the CP MAS ${ }^{13} \mathrm{C}$ NMR spectra of racemate 1 recrystallized from water, aggregated from water, and recrystallized from ethanol (the

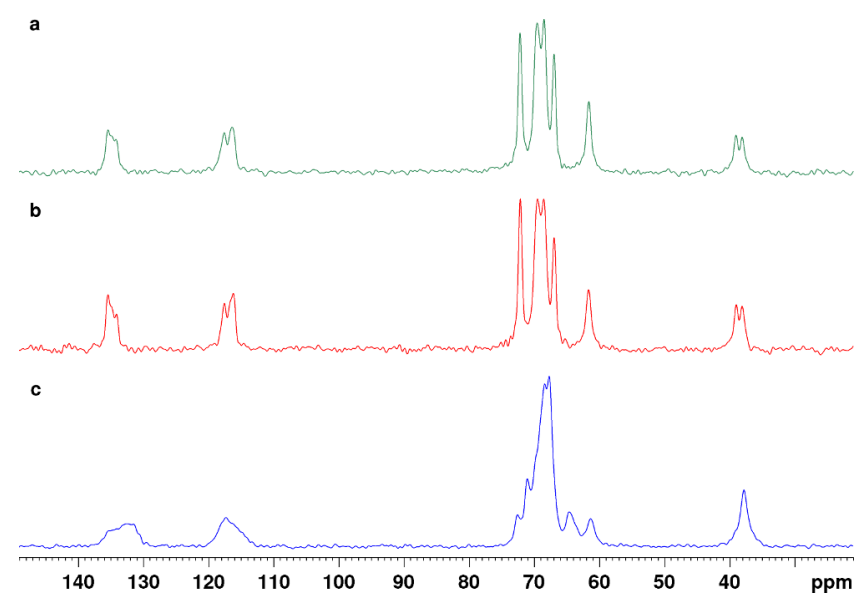

Figure 12. CP MAS ${ }^{13} \mathrm{C}$ NMR spectra of racemate 1 recrystallized from water (a), aggregated from water (b), and recrystallized from ethanol (c).

spectra of 1a are found in ESI). As expected, the CP MAS ${ }^{13} \mathrm{C}$ NMR spectra of the racemate samples acquired from water are identical, whereas the spectrum of racemate form 1-II from ethanol shows significant differences compared with the former. Interestingly, the signals originating from the allylic tail $(\delta=$ $110-120$ and $130-140 \mathrm{ppm}$ ) are all split in the case of form 1I. The splitting is most likely caused by the disorder of the allylic moiety. This assumption agrees well with the disorder model evidenced by the single crystal structure analysis. The signals in the double bond region of the CP MAS ${ }^{13} \mathrm{C}$ NMR spectrum of the polymorph 1-II are broad and uneven, possibly indicating disorder and the presence of amorphous content in the sample. The XRD analysis of polymorph 1-II (Figure 8) shows broadened diffraction peaks and higher baseline, which generally indicate a lower degree of crystallinity and the presence of amorphous form, thereby being consistent with the CP MAS ${ }^{13} \mathrm{C}$ NMR spectroscopy results.

\section{CONCLUSIONS}

In this work, a thorough investigation of the solid-state nature of racemic allylated mannose was conducted. DSC analysis, solid-state NMR spectroscopy, crystallographic data, and hot stage microscopy demonstrate that racemic allylated mannose forms a true racemate. Furthermore, the solid-state investigations showed that racemic allylated mannose exhibits abundant polymorphism.

In addition to the solid-state analysis, propargylated Dmannose and the hydrogenated analogue were prepared and subjected to conformational analysis by solution-state NMR spectroscopy. This analysis showed that the close to perfectly linear conformations of these unique molecules are not solventdependent but are maintained even in aprotic solvents. 
However, the ability to form aggregates is lost in DMSO, thus stating that linearity alone is not sufficient to promote selfassembly. The findings from this study will be utilized in our ongoing work of applying these linear, chain-elongated mannose derivatives as small-molecular rods in material science applications. In the following steps, we aim to investigate how much the hydrophobic chain can be modified in terms of chain length and functionality, while still preserving the ability to form hydrogen-bonded, rod-like aggregates. Postfunctionalizations of the allylic double bond and propargyl group are likewise in progress.

\section{ASSOCIATED CONTENT}

\section{S Supporting Information}

The Supporting Information is available free of charge on the ACS Publications website at DOI: 10.1021/acs.cgd.8b00263.

NMR data and spectra, details for DSC measurements, and X-ray diffraction data (PDF)

\section{Accession Codes}

CCDC $1822426-1822427$ and 1825936 contain the supplementary crystallographic data for this paper. These data can be obtained free of charge via www.ccdc.cam.ac.uk/data request/ cif, or by emailing data_request@ccdc.cam.ac.uk, or by contacting The Cambridge Crystallographic Data Centre, 12 Union Road, Cambridge CB2 1EZ, UK; fax: +44 1223336033.

\section{AUTHOR INFORMATION}

\section{Corresponding Author}

*Phone: +358 400707 195. E-mail: reko.leino@abo.fi.

\section{ORCID $\odot$}

\section{Reko Leino: 0000-0002-1111-9125}

\section{Present Addresses}

$\S$ (AS) School of Chemistry, University of Bristol, Bristol BS8 1TH, United Kingdom.

\#(AG) Radiopharmaceutical Chemistry Laboratory, Turku PET Centre, University of Turku, 20500 Turku, Finland.

\section{Funding}

Author IM received funding from the doctoral network Graduate School in Chemical Engineering and the Parliament Office Commission of the Åland Parliament. Authors ML and AP received funding from the Academy of Finland, project no 277250.

\section{Notes}

The authors declare no competing financial interest.

\section{ACKNOWLEDGMENTS}

This work is part of the activities at the Johan Gadolin Process Chemistry Centre, financed by Åbo Akademi. I.M. greatly acknowledges financing from the Graduate School of Chemical Engineering and the Parliament Office Commission of the Åland Parliament. M.L. and A.P kindly acknowledge the financial support from the Academy of Finland (project no. 277250). Dr. Jari Sinkkonen, Dr. Elina Puljula, and Lassi Raivonen at the Åbo Akademi University and University of Turku Instrument Centre are gratefully acknowledged for assisting with solid state NMR experiments. Dr. Jani Rahkila is acknowledged for support with solution state NMR experiments and general laboratory issues. Dr. Filip Ekholm at Helsinki University is thanked for HRMS analyses.

\section{REFERENCES}

(1) Eliel, E. L.; Wilen, S. H. Stereochemistry of Organic Compounds; John Wiley \& Sons, Inc.: New York, 1994; Chapter 6, pp 153-296.

(2) Lorenz, H.; Perlberg, A.; Sapoundjiev, D.; Elsner, M. P.; SeidelMorgenstern, A. Crystallization of enantiomers. Chem. Eng. Process. 2006, 45, 863-873.

(3) Estime, N.; Pena, R.; Teychené, S.; Autret, J. M.; Biscans, B. Characterization of the conglomerate form of acetyl-dl-leucine by thermal analysis and solubility measurements. J. Cryst. Growth 2012, $342,28-33$.

(4) Li, Y.; Zhao, Y.; Zhang, Y. Solid tryptophan as a pseudoracemate: physiochemical and crystallographic characterization. Chirality 2015, 27, 88-94.

(5) Minh, T. Le; von Langermann, J.; Lorenz, H.; SeidelMorgenstern, A. Enantiomeric 3-chloromandelic acid system: binary melting point phase diagram, ternary solubility phase diagrams and polymorphism. J. Pharm. Sci. 2010, 99, 4084-4095.

(6) Bernstein, J. Polymorphism in Molecular Crystals; Clarendon Press: Oxford, 2002; pp 1-28.

(7) Giron, D. Thermal analysis, microcalorimetry and combined techniques for the study of pharmaceuticals. J. Therm. Anal. Calorim. 1999, 56, 1285-1304.

(8) Giron, D.; Piechon, P.; Goldbronn, C.; Pfeffer, S. Thermal analysis, microcalorimetry and combined techniques for the study of the polymorphic behaviour of a purine derivative. J. Therm. Anal. Calorim. 1999, 57, 61-73.

(9) Schaefer, J. Encyclopedia of Magnetic Resonance; John Wiley \& Sons, Ltd: Chichester, UK, 2007.

(10) Harris, R. K. Applications of solid state NMR to pharmaceutical polymorphism and related matters. J. Pharm. Pharmacol. 2007, 59, 225-239.

(11) Díaz, L. E.; Morin, F.; Mayne, C. L.; Grant, D. M.; Chang, C. Conformational analysis of dl-, l- and d-methionine by solid-state NMR spectroscopy. Magn. Reson. Chem. 1986, 24, 167-170.

(12) Wang, Y.; Wilson, D.; Harbison, G. S. Solid state NMR and the crystallization of aspartic and glutamic acids. Cryst. Growth Des. 2016, $16,625-631$.

(13) Saloranta, T.; Peuronen, A.; Dieterich, J. M.; Ruokolainen, J.; Lahtinen, M.; Leino, R. From mannose to small amphiphilic polyol: perferct linearity leads to spontaneous aggregation. Cryst. Growth Des. 2016, 16, 655-661.

(14) PERCH Solutions, Kuopio, Finland, 2014.

(15) Agilent ChrysAlis Pro; Agilent Technologies Ltd.: Yarnton, England, 2010.

(16) Sheldrick, G. M. A short history of SHELX. Acta Crystallogr., Sect. A: Found. Crystallogr. 2008, 64, 112-122.

(17) Dolomanov, O. V.; Bourhis, L. J.; Gildea, R. J.; Howard, J. A. K.; Puschmann, H. OLEX2: a complete structure solution, refinement and analysis program. J. Appl. Crystallogr. 2009, 42, 339-341.

(18) Kim, E.; Gordon, D. M.; Schmid, W.; Whitesides, G. M. Tinand indium-mediated allylation in aqueous media: application to unprotected carbohydrates. J. Org. Chem. 1993, 58, 5500-5507.

(19) Saloranta, T.; Müller, C.; Vogt, D.; Leino, R. Converting unprotected monosaccharides into functionalized lactols in aqueous media: metal-mediated allylation combined with tandem hydroformylation-cyclization. Chem. - Eur. J. 2008, 14, 10539-10542.

(20) Crich, D.; Navuluri, C. Practical syntheis of 2-keto-3-deoxy-dglycero-d-galactononulosonic acid (KDN). Org. Lett. 2011, 13, 62886291.

(21) Fusaro, M. B.; Chagnault, V.; Josse, S.; Postel, D. Metal-free oxidative lactonization of carbohydrates using molecular iodine. Tetrahedron 2013, 69, 5880-5883.

(22) Wei, X.-F.; Shimizu, Y.; Kanai, M. An expeditious synthesis of sialic acid derivatives by copper(I)-catalyzed stereodivergent propargylation of unprotected aldoses. ACS Cent. Sci. 2016, 2, 21-26.

(23) Hawkes, G. E.; Lewis, D. ${ }^{1} \mathrm{H}$ Nuclear magnetic resonance spectra and conformations of alditols in deuterium oxide. J. Chem. Soc., Perkin Trans. 2 1984, 2073-2078. 
(24) Lewis, D. ${ }^{1} \mathrm{H}$ Nuclear magnetic resonance spectra and conformations of six heptitols in deuterium oxide. J. Chem. Soc., Perkin Trans. 2 1986, 467-470.

(25) Lewis, D.; Angyal, S. J. ${ }^{1}$ H N.M.R spectra and conformations of three heptitols in deuterium oxide. J. Chem. Soc., Perkin Trans. 2 1989, $1763-1765$.

(26) Gillies, D. G.; Lewis, D. ${ }^{1} \mathrm{H}$ Nuclear magnetic resonance spectra and conformations of deoxyalditols in deuterium oxide. J. Chem. Soc., Perkin Trans. 2 1985, 1155-1159.

(27) Matsumori, N.; Kaneno, D.; Murata, M.; Nakamura, H.; Tachibana, K. Stereochemical determination of acyclic structures based on carbon-proton spin-coupling constants. A method of configuration analysis for natural products. J. Org. Chem. 1999, 64, 866-876.

(28) Tamman, G. The States of Aggregation; Constable and Company: London, 1926; pp 116-157.

(29) $\mathrm{Yu}, \mathrm{L}$. Inferring thermodynamic stability relationship of polymorphs from melting data. J. Pharm. Sci. 1995, 84, 966-974.

(30) Burger, A.; Ramberger, R. On the polymorphism of pharmaceuticals and other molecular crystals. Microchim. Acta 1979, 72, 259-271. 